\title{
Dietary patterns associated with meeting the WHO free sugars intake guidelines
}

\author{
Courtney Steele ${ }^{1,2}$, Helen Eyles ${ }^{3}$, Lisa Te Morenga ${ }^{4}$, Cliona Ni Mhurchu ${ }^{3,5}$ and \\ Christine Cleghorn ${ }^{2, *}$
}

'Department of Human Nutrition, University of Otago, P.O. Box 56, Dunedin 9054, New Zealand: ${ }^{2}$ Department of Public Health, University of Otago, Wellington, P.O. Box 7343, Wellington 6242, New Zealand: ${ }^{3}$ National Institute for Health Innovation, School of Population Health, The University of Auckland, Private Bag 92019, Auckland Mail Centre, Auckland 1 142, New Zealand: "Faculty of Health, Victoria University of Wellington, P.O. Box 600,

Wellington 6140, New Zealand: ${ }^{5}$ Food Policy Division, The George Institute for Global Health, Level 5/1 King Street, Newtown NSW 2042, Australia

Submitted 14 April 2019: Final revision received 16 0ctober 2019: Accepted 25 0ctober 2019: First published online 8 April 2020

\begin{abstract}
Objective: Emerging evidence suggests that free sugars intake in many countries exceeds that recommended by the WHO. However, information regarding realworld dietary patterns associated with meeting the WHO free sugars guidelines is lacking. The current study aimed to determine dietary patterns associated with meeting the guidelines to inform effective free sugars reduction interventions in New Zealand (NZ) and similar high-income countries.

Design: Dietary patterns were derived using principal component analysis on repeat 24-h NZ Adult Nutrition Survey dietary recall data. Associations between dietary patterns and the WHO guidelines ( $<5$ and $<10 \%$ total energy intake) were determined using logistic regression analyses.

Setting: New Zealand.

Participants: NZ adults ( $n$ 4721) over 15 years old.

Results: Eight dietary patterns were identified: 'takeaway foods and alcohol' was associated with meeting both WHO guidelines; 'contemporary' was associated with meeting the $<10 \%$ guideline (males only); 'fast foods, sugar-sweetened beverages and dessert', 'traditional' and 'breakfast foods' were negatively associated with meeting both guidelines; 'sandwich' and 'snack foods' were negatively associated with the $<5 \%$ guideline; and 'saturated fats and sugar' was negatively associated with the $<10 \%$ guideline.

Conclusions: The majority of NZ dietary patterns were not consistent with WHO free sugars guidelines. It is possible to meet the WHO guidelines while consuming a healthier ('contemporary') or energy-dense, nutrient-poor ('takeaway foods and alcohol') diet. However, the majority of energy-dense patterns were not associated with meeting the guidelines. Future nutrition interventions would benefit from focusing on establishing healthier overall diets and reducing consumption and free sugars content of key foods.
\end{abstract}

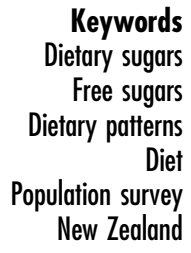

Evidence of the relationship between dietary sugars and adverse health outcomes has caused sugars to become a subject of public health concern ${ }^{(1-7)}$. In 2015, the WHO released a sugars intake guideline recommending a reduction of dietary free sugars ${ }^{(8)}$ based on evidence that a diet high in free sugars would lead to weight gain (low- and moderate-quality evidence) and dental caries (very-lowand moderate-quality evidence $)^{(1,2)}$. Free sugars are defined by the WHO as 'monosaccharides and disaccharides added to foods and beverages by the manufacturer, cook or consumer, and sugars naturally present in honey, syrups, fruit juices and fruit juice concentrates' ${ }^{(8)}$. Free sugars are, therefore, predominantly found in non-nutritive energy-dense foods such as sugar-sweetened beverages (SSB) and confectionary $^{(9)}$. The WHO guideline strongly recommends that free sugars intake be reduced to $<10 \%$ of total energy 
(TE) intake ${ }^{(8)}$, the equivalent of approximately twelve teaspoons of sugar per day for adults. The WHO made a further conditional recommendation that intakes be reduced to $<5 \%$ TE for additional health benefits ${ }^{(8)}$.

Nationally representative dietary surveys from several high-income countries have indicated typical free sugars intakes exceeding the WHO recommendations, including the Netherlands $(14.2 \% \mathrm{TE})^{(10)}$, Australia $(11.7 \% \mathrm{TE})^{(9)}$, the UK (12.3\% TE from non-milk extrinsic sugars) ${ }^{(11)}$ and the USA $(14.6 \% \text { TE from added sugars })^{(12)}$. Similarly, recent analyses using 2008/2009 NZ Adult Nutrition Survey (NZANS) data have found that New Zealand (NZ) adults (over 15 years) consume more free sugars than the WHO guidance (median intake $57 \mathrm{~g} / \mathrm{d}$ or $11 \% \mathrm{TE}$, the equivalent of 14.3 teaspoons of sugar) ${ }^{(13)}$. The majority (58\%) of NZ adults do not meet the $<10 \%$ WHO recommendation ${ }^{(13)}$. However, this figure likely underestimates the true free sugars intake of NZ adults; an estimated $21 \%$ of men and $25 \%$ of women underreported energy intake in the NZANS ${ }^{(14)}$, and it is likely that underreporting was exacerbated for foods containing free sugars as individuals are more likely to underreport energy-dense foods ${ }^{(15)}$.

New Zealand has the third highest adult obesity rate among countries in the Organisation for Economic Cooperation and Development (OECD) ${ }^{(16)}$, and almost one in three $(32 \%) \mathrm{NZ}$ adults and one in eight (12\%) children are now obese ${ }^{(17)}$. This is an increase from $27 \%$ of adults and $8 \%$ of children in $2006 / 2007^{(17)}$. The increasing prevalence of obesity has occurred in parallel with greater availability of total sugars in NZ, which increased from approximately $135 \mathrm{~g}$ per capita per day in 1982/1984 to $160 \mathrm{~g}$ per capita per day in $2000 / 2002^{(18)}$. Dental decay also remains the most prevalent chronic disease in $\mathrm{NZ}^{(19)}$. The 2009 NZ Oral Health Survey reported that dentate NZ adults had a mean of fourteen decayed, missing or filled teeth, and one in three dentate adults (35\%) had untreated coronal decay (decay on the visible crown of the tooth) ${ }^{(19)}$

It is evident that interventions and policies are urgently required to reduce dietary free sugars. Such interventions would benefit from focusing on both dietary patterns, that is, the way in which foods and beverages are combined to form a complete diet ${ }^{(20)}$, and specific foods where consumption could be reduced or products reformulated. The causes of obesity and dental caries are multifactorial, and dietary risk factors are additive in their effects ${ }^{(21)}$. Consequently, it is unlikely that disease prevalence can be attributed solely to one food or beverage. Dietary pattern analysis is, thus, advantageous as it acknowledges that nutrients such as free sugars are not consumed in isolation $^{(20,22)}$. Additionally, dietary patterns may be easily translated into population dietary guidelines, and educational interventions as food-based recommendations are more easily understood and adopted by the general public than single-nutrient recommendations ${ }^{(20)}$. Focusing on dietary patterns has, thus, been suggested as the most effective method for achieving dietary guidelines ${ }^{(20)}$.

Our primary aim was, therefore, to determine the dietary patterns associated with meeting the WHO free sugars guideline $(<5$ and $<10 \% \mathrm{TE})$. Secondary aims were to determine the dietary patterns associated with moderate and high intakes of free sugars, and whether dietary patterns low, moderate or high in free sugars differ by sex, age or ethnicity.

\section{Methods}

\section{Study design and population}

NZANS, NZ's most recent national nutrition survey, was conducted between October 2008 and October 2009. A full report of the NZANS methodology can be found on the Ministry of Health website ${ }^{(23)}$. Briefly, $4721 \mathrm{NZ}$ adults over 15 years living in permanent private residences were recruited, with sufficient sampling of Māori (Indigenous New Zealanders), Pacific Islanders, and younger and older age groups to produce robust data for all major ethnic and age groups. A multi-stage, stratified, probability-proportionalto-size sample design was used. Survey weights were developed to ensure results were representative of all NZ adults. Trained interviewers collected dietary data during face-to-face 90-min interviews administered in participants' homes using a computer-based multiple-pass 24-h diet recall. Researchers distributed interviews across all days of the week. To allow for the estimation of usual intake of nutrients, a repeat 24-h diet recall was conducted on a random subsample of $25 \%$ of participants ( $n$ 1180).

\section{Data preparation}

Prior to analysis, the thirty-three initial NZANS food groups $^{(24)}$ were adapted into thirty-four new food groups, which would produce easily interpretable dietary patterns associated with free sugars intake (Table 1). For example, 'non-alcoholic beverages' were separated into 'low-sugar beverages' and 'sugar-sweetened beverages' on the basis of whether or not the mean total sugar content of a particular subgroup met the cut-off for the lower rate of the UK Soft Drinks Industry Levy (drinks containing added sugars with a total sugar content $\geq 5 \mathrm{~g} / 100 \mathrm{ml}^{(25)}$ ). The food groups 'beef and veal', 'lamb and mutton', and 'pork' were aggregated into an overarching 'red meats' food group based on health outcomes associated with red meat consumption ${ }^{(26)}$.

Usual dietary intake, rather than a single day's dietary intake, was used in the present study to account for intraindividual variability. To determine usual intake, participants' intakes of each food group were adjusted using repeat 24-h diet recall data and the Multiple Source Method (MSM) ${ }^{(27)}$. Analyses were performed by sex, and it was assumed that all participants were habitual consumers of each food group in the absence of FFQ data. 
Table 1 Food groups used in dietary pattern analyses

\begin{tabular}{|c|c|c|}
\hline No. & Food group & Examples of food items included \\
\hline 1 & Grains and pasta & $\begin{array}{l}\text { Rice (boiled, fried, risotto, sushi, salad), flour, pasta/noodles, bran, cereal-based products and } \\
\text { dishes (pasta and sauce, lasagne, pasta salad, noodle soup, chow mein) }\end{array}$ \\
\hline 2 & Bread and sandwiches* & $\begin{array}{l}\text { All types of bread (rolls, pita, focaccia, garlic), sandwiches, filled rolls, filled pita breads, } \\
\text { croissants, bagels, crumpets, sweet buns, bread-based stuffings }\end{array}$ \\
\hline 3 & Breakfast cereals & All types (muesli, wheat biscuits, porridge, puffed/flaked/extruded cereals) \\
\hline 4 & Crackers $^{*}$ & Single and multigrain crackers, rice wafers and crackers, high- and low-fat varieties \\
\hline 5 & Biscuits* & Plain, chocolate-coated, fruit-filled, cream-filled and fruit and/or nut biscuits \\
\hline 6 & Cakes and muffins & All cakes and muffins, slices, scones, pancakes, pikelets, waffles, doughnuts, pastry \\
\hline 7 & Takeaway foods* & $\begin{array}{l}\text { Burgers, hot-dogs, pizza, tortillas, tacos, doner kebabs, burritos, nachos, dim sims, spring rolls, } \\
\text { wontons, bread-based batters }\end{array}$ \\
\hline 8 & Puddings and desserts* & $\begin{array}{l}\text { Milk puddings, ice-cream, cheesecakes, fruit crumbles, mousse, steamed sponges, sweet pies, } \\
\text { pavlova, meringues }\end{array}$ \\
\hline 9 & Milk* & All milk (cow, soya, rice, and goat) and milk powder \\
\hline 10 & Dairy products & Cream, sour cream, yoghurt, dairy food, dairy-based dips \\
\hline 11 & Cheese & $\begin{array}{l}\text { Cheddar, Edam, specialty (blue, brie, feta, etc.), ricotta, cream cheese, cottage cheese, } \\
\text { processed cheese }\end{array}$ \\
\hline 12 & Unsaturated fats* & Margarine and canola, olive, sunflower, sesame, peanut and vegetable oils \\
\hline 13 & Saturated fats* & Butter, butter/margarine blends, coconut oil, dripping, lard, chefade, palm oil, suet \\
\hline 14 & Eggs and egg dishes & All eggs (poached, boiled, scrambled and fried), omelettes, self-crusting quiches, egg stir-fries \\
\hline 15 & Poultry & All chicken, duck, turkey and mutton-bird muscle meats and processed meat, stews and stir-fries \\
\hline 16 & Fish and seafood & $\begin{array}{l}\text { All fish (fresh, frozen, smoked, canned, battered and fingers), shellfish, squid, crab, shrimp/ } \\
\text { prawns, fish/seafood dishes (pies, casseroles and fritters), fish and seafood products }\end{array}$ \\
\hline 17 & Red meats* & $\begin{array}{l}\text { All beef and veal (all muscle meats including steak, mince, corned beef, roast and schnitzel, and } \\
\text { stews, stir-fries and curries), lamb and mutton (all muscle meats including chops, roast and } \\
\text { mince, and stews, stir-fries and curries), pork (all muscle meats including roast, chop, steak } \\
\text { and schnitzel, and bacon, ham, stews and stir-fries) }\end{array}$ \\
\hline 18 & Sausages and processed meats & Sausages, luncheon, frankfurters, saveloys/cheerios, salami, meatloaf and patties \\
\hline 19 & Other meat & Venison, rabbit, goat, organ meats (liver, kidney, heart, tongue), pâté, haggis \\
\hline 20 & Pies and pasties & All pies including potato top, pasties, savouries, sausage rolls, quiche with pastry \\
\hline 21 & Vegetables & $\begin{array}{l}\text { All vegetables (fresh, frozen, canned) including mixes, coleslaw, tomatoes, green salads, } \\
\text { legumes and pulses, legume products and dishes (baked beans, hummus, tofu), vegetable } \\
\text { dishes }\end{array}$ \\
\hline 22 & Potatoes, kumara and taro & $\begin{array}{l}\text { Mashed, boiled, baked potatoes and kumara, potato dishes (stuffed, scalloped potatoes), taro } \\
\text { roots and stalks }\end{array}$ \\
\hline 23 & Potato products* & Hot chips, wedges, croquettes and hash browns, crisps \\
\hline 24 & Snack foods* & $\begin{array}{l}\text { Corn chips, popcorn, extruded snacks and other crisps (grain, kumara, etc.), fruit leathers/roll } \\
\text { ups }\end{array}$ \\
\hline 25 & Snack bars & Muesli bars, wholemeal fruit bars, puffed cereal bars, nut and seed bars \\
\hline 26 & Fruit $^{\star}$ & All fruit, fresh, canned, cooked and dried \\
\hline 27 & Nuts and seeds & $\begin{array}{l}\text { All nuts (including peanuts, almonds, etc.), all seeds (including sesame, sunflower, pumpkin), } \\
\text { nut butters and chocolate nut spreads, coconut (including milk and cream), nut-based dips } \\
\text { (pesto's) }\end{array}$ \\
\hline 28 & Sugar and sweets & $\begin{array}{l}\text { Sugars, syrups, confectionery, chocolate, jam, marmalade, honey, jelly, sweet toppings and } \\
\text { icing, ice-blocks }\end{array}$ \\
\hline 29 & Soups and stocks & All instant and homemade soups (excluding noodle soups), stocks and stock powders \\
\hline 30 & Savoury sauces and condiments & $\begin{array}{l}\text { Gravies, tomato and cream-based sauces, soya, tomato and other sauces, cheese sauces, } \\
\text { mayonnaise, oil and vinegar dressings, chutney, marmite }\end{array}$ \\
\hline 31 & Low-sugar beverages* & $\begin{array}{l}\text { Tea (including black tea, herbal tea, green tea), coffee, diet soft drinks, water (including mineral } \\
\text { and soda water, tap and filtered water), sweetened water, other non-alcoholic beverages }\end{array}$ \\
\hline 32 & Sugar-sweetened beverages* & $\begin{array}{l}\text { Hot drinks (including Milo, hot chocolate, cocoa, cereal beverages, etc.), milkshakes, flavoured } \\
\text { milk, fruit juices (including apple, orange, grapefruit and grape), vegetable juices, cordials and } \\
\text { fruit drinks, regular soft drinks, sports drinks, energy drinks, powdered drinks }\end{array}$ \\
\hline 33 & Alcoholic beverages & Wine, beer, ciders, spirits, liqueurs and cocktails, ready-to-drink alcoholic sodas \\
\hline 34 & $\begin{array}{l}\text { Dietary supplements providing } \\
\text { energy }\end{array}$ & Meal replacements, protein supplements (powders and bars) \\
\hline
\end{tabular}

*Food groups differ from original food groups in the New Zealand Adult Nutrition Survey.

\section{Derivation and analysis of dietary patterns}

Following a literature review of the strengths and limitations of a posteriori dietary pattern derivation methods ${ }^{(28)}$, no one method appeared better than another. Principal component analysis (PCA) was selected as the most appropriate method to derive dietary patterns in the present study. PCA is a data reduction technique in which $x$ correlated foods or food groups are entered and transformed to produce a smaller number of $y$ uncorrelated variables ${ }^{(29)}$. The uncorrelated variables produced are components that represent unique dietary patterns.

PCA was conducted on usual dietary intake $(\mathrm{g} / \mathrm{d})$ for the thirty-four food groups using the survey-weighted correlation matrix. The Kaiser-Meyer-Olkin measure of sampling 
adequacy $(0.57 ;>0.5$ acceptable $)$ and Bartlett's test of sphericity $(P<0.001 ; P<0.001$ acceptable) were used to ensure that correlation within the dataset was adequate for performing PCA. Resulting components were retained on the basis of having an eigenvalue $>1 \cdot 0$, their position on a scree plot (before an 'elbow') and their interpretability. An orthogonal varimax rotation was used to improve the interpretability of components ${ }^{(29,30)}$. Rotated components were named based on food groups with component loadings $> \pm 0 \cdot 2$. Component loadings depict correlations between each food group and dietary pattern. Food groups with a component loading $>+0 \cdot 2$ or $>-0.2$ for a particular dietary pattern positively or negatively characterised that pattern respectively, indicating high or low intakes of the food group for participants adhering to the pattern. The larger the positive or negative component loading, the more meaningfully that food group characterised the dietary pattern.

Component scores were extracted as standardised values with a mean of zero and variance of one. Component scores, indicating how closely a participant adhered to a particular dietary pattern, were adjusted for in all logistic regression models. PCA does not produce mutually exclusive dietary patterns. Therefore, participants received a component score for each of the retained dietary patterns, with half of the population receiving positive scores and half receiving negative scores.

\section{Statistical analyses}

Stata/IC $15.0^{(31)}$ was used to conduct all statistical analyses, except for the estimation of usual intake of nutrients where MSM was used. All survey data, except for specified sociodemographic data presented in Table 2, were weighted,

Table 2 Unweighted and survey-weighted characteristics of the 4721 participants in the New Zealand Adult Nutrition Survey

\begin{tabular}{|c|c|c|c|c|}
\hline & \multicolumn{2}{|c|}{$\begin{array}{l}\text { Total population } \\
\text { (unweighted) } \\
\text { ( } n \text { 4721) }\end{array}$} & \multicolumn{2}{|c|}{$\begin{array}{c}\text { Total population } \\
\text { (survey-weighted) } \\
(n 4721)\end{array}$} \\
\hline & $\%$ & $n$ & $\%$ & $n$ \\
\hline \multicolumn{5}{|l|}{ Sex } \\
\hline Male & $43 \cdot 8$ & 2066 & $47 \cdot 8$ & 2257 \\
\hline Female & $56 \cdot 2$ & 2655 & $52 \cdot 2$ & 2464 \\
\hline \multicolumn{5}{|l|}{ Age (years) } \\
\hline$\leq 30$ & $30 \cdot 0$ & 1417 & $27 \cdot 1$ & 1279 \\
\hline$>30$ & $70 \cdot 0$ & 3304 & 72.9 & 3442 \\
\hline \multicolumn{5}{|l|}{ Ethnicity } \\
\hline Māori & $22 \cdot 0$ & 1040 & $11 \cdot 3$ & 535 \\
\hline Pacific & 14.8 & 701 & 4.8 & 227 \\
\hline NZEO & $63 \cdot 1$ & 2980 & 83.9 & 3959 \\
\hline BMI $\left(\mathrm{kg} / \mathrm{m}^{2}\right)^{\star}$ & 27.4 & $23 \cdot 9,31 \cdot 8$ & $26 \cdot 6$ & $23 \cdot 6,30 \cdot 4$ \\
\hline Energy intake $(\mathrm{kJ})^{*}$ & 8333 & 6605,10454 & 8646 & 7001,1074 \\
\hline $\begin{array}{l}\text { Free sugars intake } \\
(\mathrm{g} / \mathrm{d})^{*}\end{array}$ & $55 \cdot 0$ & $33.2,83.5$ & $57 \cdot 3$ & $35 \cdot 0,84 \cdot 3$ \\
\hline $\begin{array}{l}\text { Free sugars intake } \\
(\% \mathrm{TE})^{\star}\end{array}$ & $11 \cdot 2$ & $7 \cdot 4,15 \cdot 6$ & $11 \cdot 1$ & $7 \cdot 3,15 \cdot 4$ \\
\hline
\end{tabular}

NZEO, New Zealand European and other; TE, total energy.

${ }^{*}$ Median (25th, 75th percentiles). and survey commands were used to produce proportions, medians, percentiles, OR and $95 \%$ CI. Subpopulation commands were used for estimates by sex, age group ( $\leq 30$ and $>30$ years) and ethnicity (Māori, Pacific, or New Zealand European and other (NZEO)). Prioritised ethnicity was used with the following order of prioritisation: Māori, Pacific and NZEO. When stratifying the population by sex, age, ethnicity or free sugars intake, it was ensured that there were a sufficient number of participants in each stratum (defined as $n \geq 30^{(24)}$ ) to produce robust results.

Total intakes of free sugars were calculated in 2017 by Kibblewhite et al. ${ }^{(13)}$ for all foods and beverages consumed by NZANS participants based on the methods outlined by Louie et $a l{ }^{(32)}$. Free sugars were defined in the study by Kibblewhite et $a l .{ }^{(13)}$ and in the present study using the WHO definition of 'monosaccharides and disaccharides added to foods and beverages by the manufacturer, cook or consumer, and sugars naturally present in honey, syrups, fruit juices and fruit juice concentrates' ${ }^{\text {(8) }}$. Total consumption of free sugars was used to categorise each participant as meeting the $<5$ or $<10 \%$ WHO free sugars guidelines or not meeting the WHO guidelines. Maximum-likelihood logistic regression models were subsequently fitted to determine which of the resulting dietary patterns were associated with meeting the $<5$ and $<10 \%$ WHO free sugars guidelines. The dichotomous dependent variable used in each model indicated whether participants met or did not meet the $<5$ or $<10 \%$ WHO free sugars guideline. Models were adjusted for sex, age, prioritised ethnicity and component score for all derived dietary patterns. OR (and $95 \% \mathrm{CI}$ ) were calculated for the total population and by sex, age and prioritised ethnicity.

\section{Results}

\section{Sociodemographics}

Table 2 describes the unweighted and survey-weighted characteristics of the 4721 NZANS participants. Unweighted values depict characteristics of the NZANS study population. Survey-weighted values depict characteristics of the NZ population. Compared with the total NZ population, the study population comprised a slightly higher proportion of females $(56 v .52 \%)$ and adults $\leq 30$ years (30v. $27 \%$ ), and oversampled Māori (22 v. $11 \%$ ) and Pacific (15v. 5\%).

Table 3 shows the proportion of survey participants who met the $<5 \%$ TE free sugars guideline (low free sugars), met the $<10 \%$ TE but did not meet the $<5 \%$ TE free sugars guideline (moderate free sugars), and who met neither (high free sugars). Less than one in eight (12\%) met the $<5 \%$ WHO guideline, and fewer than one in three ( $42 \%)$ met the $<10 \%$ WHO guideline.

A significantly higher proportion of adults $>30$ years met the $<5$ and $<10 \%$ WHO free sugars guidelines (14 and $34 \%$, respectively) than adults $\leq 30$ years ( 7 and $20 \%$, 
Table 3 Survey-weighted proportion of participants meeting the WHO $<5 \%$ and $<10 \%$ TE free sugars guideline and not meeting the guideline by sex, age and prioritised ethnicity

\begin{tabular}{|c|c|c|c|c|c|c|}
\hline & \multicolumn{2}{|c|}{$\begin{array}{l}\text { Low free sugars } \\
\qquad\left(<5 \% \mathrm{TE}^{\star}\right)\end{array}$} & \multicolumn{2}{|c|}{$\begin{array}{l}\text { Moderate free sugars } \\
\quad(5-10 \% \mathrm{TE} \dagger)\end{array}$} & \multicolumn{2}{|c|}{$\begin{array}{l}\text { High free sugars } \\
(>10 \% \mathrm{TE})\end{array}$} \\
\hline & $\%$ & $n$ & $\%$ & $n$ & $\%$ & $n$ \\
\hline & 11.9 & 562 & 29.9 & 1413 & $58 \cdot 2$ & 2745 \\
\hline \multicolumn{7}{|l|}{ Sex } \\
\hline Male & $12 \cdot 2$ & 274 & 28.9 & 652 & 59.0 & 1331 \\
\hline Female & $11 \cdot 7$ & 288 & $30 \cdot 9$ & 761 & $57 \cdot 4$ & 1414 \\
\hline \multicolumn{7}{|l|}{ Age (years) } \\
\hline$\leq 30$ & $7 \cdot 4$ & 94 & $19 \cdot 8$ & 253 & $72 \cdot 9$ & 932 \\
\hline$>30$ & $13 \cdot 6$ & 468 & 33.7 & 1160 & 52.7 & 1813 \\
\hline \multicolumn{7}{|l|}{ Ethnicity } \\
\hline Māori & $11 \cdot 3$ & 61 & $27 \cdot 7$ & 148 & $61 \cdot 0$ & 326 \\
\hline Pacific & 14.9 & 34 & 30.4 & 69 & 54.7 & 124 \\
\hline NZEO & $11 \cdot 8$ & 468 & $30 \cdot 2$ & 1196 & 58.0 & 2295 \\
\hline BMI $\left(\mathrm{kg} / \mathrm{m}^{2}\right) \ddagger$ & $26 \cdot 9$ & $24 \cdot 1,31 \cdot 7$ & $27 \cdot 1$ & $23 \cdot 8,30 \cdot 3$ & $26 \cdot 4$ & $23 \cdot 3,30 \cdot 2$ \\
\hline Energy intake (kJ)‡ & 8097 & 6566,10665 & 8282 & 6776,10326 & 8932 & 7218,10961 \\
\hline Free sugars intake $(\mathrm{g} / \mathrm{d}) \ddagger$ & $15 \cdot 1$ & $11 \cdot 4,22.9$ & $37 \cdot 6$ & $28 \cdot 9,48 \cdot 7$ & 77.9 & $59 \cdot 8,106 \cdot 0$ \\
\hline Free sugars intake (\% TE) $\ddagger$ & 3.5 & $2 \cdot 4,4 \cdot 4$ & $7 \cdot 7$ & $6.4,8.9$ & $14 \cdot 6$ & $12 \cdot 2,18 \cdot 0$ \\
\hline
\end{tabular}

TE, total energy; NZEO, New Zealand European and other.

${ }^{*}$ Free sugars intake $<5 \% \mathrm{TE}$, that is, met the $<5 \%$ WHO free sugars guideline.

†Free sugars intake $\geq 5 \%$ TE but $<10 \% \mathrm{TE}$, that is, met the $<10 \%$ WHO free sugars guideline only.

¥Median (25th, 75th percentiles).

respectively) (Table 3 ). No significant differences were seen by sex or ethnicity. Participants consuming a diet high in free sugars had a significantly higher mean energy intake than participants with diets moderate or low in free sugars. Median BMI did not significantly differ between NZ adults consuming a diet low, moderate or high in free sugars.

\section{Dietary patterns}

Eight dietary patterns were identified using PCA (Table 4), which explained $34 \%$ of the total variance in food group intake. Dietary pattern 1 was a 'sandwich' pattern characterised by high intakes of bread and sandwiches, unsaturated fats (including margarine), cheese, red meat and sugar and sweets (including sweet spreads). Pattern 2 was termed 'fast foods, SSB and desserts' and was characterised by high intakes of SSB, takeaway foods, puddings and desserts and pies and pasties, and low intakes of vegetables, low-sugar beverages and fruit. Pattern 3, 'traditional', was characterised by foods commonly associated with NZ culture, including high intakes of potatoes, kumara and taro, savoury sauces and condiments, vegetables, red meats, puddings and desserts, cakes and muffins, and low intakes of soups and stocks and dietary supplements. Pattern 4 was termed 'takeaway foods and alcohol' and was characterised by high intakes of potato products, fish and seafood, alcoholic beverages and takeaway foods, and low intakes of soups and stocks. Pattern 5 was termed 'breakfast foods' and was characterised by high intakes of milk, breakfast cereals, sugar and sweets, puddings and desserts and cakes and muffins, and low intakes of alcoholic beverages and eggs and egg dishes. Pattern 6 was termed 'snack foods' and was characterised by high intakes of snack bars, cheese, crackers, dairy products and fruit. Pattern 7 was termed 'saturated fats and sugar' and was characterised by high intakes of saturated fats, cheese and sugar and sweets, and low intakes of unsaturated fats and nuts and seeds. Pattern 8 was termed 'contemporary' and was characterised by high intakes of grains and pasta, poultry, snack foods, nuts and seeds and low-sugar beverages, and low intakes of biscuits.

\section{Associations between dietary patterns and the WHO free sugars recommendations}

For the total population, adherence to the 'takeaway foods and alcohol' dietary pattern was positively associated with meeting both the $<5$ and $<10 \%$ WHO guidelines (Table 5). In the total population, every SD increase in 'takeaway foods and alcohol' component score was associated with a $19 \%(1 \cdot 19 ; 95 \%$ CI $1 \cdot 04,1 \cdot 36)$ or $23 \%(1 \cdot 23 ; 95 \%$ CI $1.11,1.35)$ increase in the likelihood of meeting the $<5$ and $<10 \%$ guidelines, respectively. Males and NZEO were more likely to meet the $<5$ and $<10 \%$ recommendations, and adults $>30$ years were more likely to meet the $<10 \%$ recommendation when adhering to 'takeaway foods and alcohol'.

Adherence to the 'contemporary' pattern was neither positively nor negatively associated with meeting the $<5 \%(1.07 ; 95 \%$ CI $0.90,1.26)$ or $<10 \%(1.06 ; 95 \%$ CI $0.97,1.16)$ WHO guidelines for the total population. However, males adhering to the 'contemporary' pattern were $17 \%(1 \cdot 17 ; 95 \%$ CI $1 \cdot 04,1 \cdot 31)$ more likely to meet the $<10 \%$ recommendation.

Adherence to the 'breakfast foods' and 'fast foods, SSB and dessert' patterns was negatively associated with meeting the $<5$ and $<10 \%$ WHO guidelines for the total 
Table 4 Rotated component loadings for food groups included in the eight identified dietary patterns

\begin{tabular}{|c|c|c|c|c|c|c|c|c|}
\hline Variable & Sandwich & $\begin{array}{l}\text { Fast foods, } \\
\text { SSB and } \\
\text { desserts }\end{array}$ & Traditional & $\begin{array}{c}\text { Takeaway } \\
\text { foods and } \\
\text { alcohol }\end{array}$ & $\begin{array}{l}\text { Breakfast } \\
\text { foods }\end{array}$ & $\begin{array}{l}\text { Snack } \\
\text { foods }\end{array}$ & $\begin{array}{c}\text { Saturated } \\
\text { fats and } \\
\text { sugar }\end{array}$ & Contemporary \\
\hline Grains and pasta & 0.06 & -0.05 & -0.13 & -0.06 & 0.01 & -0.03 & 0.02 & 0.59 \\
\hline Bread and sandwiches & $0.57^{\star}$ & 0.06 & -0.08 & -0.01 & -0.01 & 0.07 & 0.13 & 0.05 \\
\hline Breakfast cereals & -0.06 & -0.02 & 0.00 & 0.06 & 0.45 & 0.06 & -0.09 & 0.00 \\
\hline Crackers & -0.01 & 0.02 & -0.05 & 0.01 & -0.04 & 0.44 & 0.14 & -0.09 \\
\hline Biscuits & 0.09 & 0.08 & 0.17 & 0.05 & 0.12 & 0.10 & -0.16 & -0.20 \\
\hline Cakes and muffins & -0.14 & $0 \cdot 16$ & 0.20 & -0.09 & 0.20 & 0.00 & 0.08 & -0.08 \\
\hline Takeaway foods & -0.03 & 0.28 & -0.13 & 0.26 & 0.03 & -0.05 & -0.04 & 0.03 \\
\hline Puddings and desserts & 0.01 & 0.23 & 0.26 & -0.13 & 0.20 & $0 \cdot 12$ & 0.02 & -0.04 \\
\hline Milk & 0.07 & -0.09 & 0.03 & $0 \cdot 11$ & 0.53 & -0.08 & 0.05 & 0.07 \\
\hline Dairy products & $-0 \cdot 15$ & -0.03 & 0.03 & 0.04 & 0.16 & 0.40 & -0.06 & -0.06 \\
\hline Cheese & 0.22 & -0.01 & -0.01 & -0.01 & -0.07 & 0.46 & 0.20 & 0.04 \\
\hline Unsaturated fats & 0.55 & -0.04 & 0.10 & -0.02 & 0.08 & -0.04 & -0.29 & -0.06 \\
\hline Saturated fats & -0.04 & -0.04 & 0.04 & -0.01 & 0.02 & 0.06 & 0.67 & 0.00 \\
\hline Eggs and egg dishes & $0 \cdot 15$ & -0.15 & 0.04 & $0 \cdot 14$ & -0.21 & -0.09 & 0.12 & $-0 \cdot 10$ \\
\hline Poultry & -0.13 & 0.13 & 0.18 & -0.03 & 0.05 & 0.00 & -0.02 & 0.51 \\
\hline Fish and seafood & 0.00 & -0.16 & -0.07 & 0.54 & 0.09 & 0.02 & 0.03 & -0.09 \\
\hline Red meats & 0.22 & 0.01 & 0.29 & -0.01 & -0.11 & -0.07 & 0.19 & -0.02 \\
\hline $\begin{array}{l}\text { Sausages and processed } \\
\text { meats }\end{array}$ & 0.14 & 0.06 & 0.18 & 0.17 & 0.02 & 0.03 & -0.17 & -0.12 \\
\hline Other meats & 0.13 & -0.15 & -0.01 & 0.01 & -0.06 & $-0 \cdot 10$ & -0.03 & -0.03 \\
\hline Pies and pasties & 0.05 & 0.23 & 0.11 & -0.05 & -0.12 & -0.03 & 0.02 & -0.07 \\
\hline Vegetables & -0.02 & -0.42 & 0.32 & 0.00 & -0.03 & 0.03 & -0.03 & 0.07 \\
\hline Potatoes, kumara and taro & -0.01 & -0.01 & 0.53 & -0.07 & 0.02 & -0.09 & 0.07 & -0.08 \\
\hline Potato products & -0.02 & 0.12 & 0.00 & 0.58 & 0.01 & -0.01 & -0.07 & -0.03 \\
\hline Snack foods & 0.08 & 0.04 & 0.03 & -0.02 & -0.07 & 0.02 & -0.15 & 0.25 \\
\hline Snack bars & -0.02 & 0.08 & -0.05 & 0.02 & -0.11 & 0.47 & -0.05 & 0.03 \\
\hline Fruit & -0.02 & -0.21 & 0.02 & -0.11 & $0 \cdot 10$ & 0.31 & -0.14 & -0.02 \\
\hline Nuts and seeds & 0.12 & -0.06 & -0.01 & -0.01 & 0.02 & 0.12 & -0.24 & 0.24 \\
\hline Sugar and sweets & 0.22 & 0.15 & -0.02 & -0.04 & 0.37 & -0.11 & 0.29 & 0.02 \\
\hline Soups and stocks & $0 \cdot 18$ & -0.02 & -0.23 & -0.26 & -0.02 & -0.02 & -0.09 & $-0 \cdot 18$ \\
\hline $\begin{array}{l}\text { Savoury sauces and } \\
\text { condiments }\end{array}$ & 0.02 & -0.03 & 0.36 & $0 \cdot 10$ & -0.03 & 0.11 & -0.07 & 0.12 \\
\hline Low-sugar beverages & 0.11 & -0.37 & -0.07 & 0.09 & 0.15 & 0.01 & 0.13 & 0.21 \\
\hline Sugar-sweetened beverages & 0.08 & 0.51 & 0.05 & 0.05 & -0.03 & 0.05 & -0.03 & 0.17 \\
\hline Alcoholic beverages & 0.06 & 0.02 & $0 \cdot 12$ & 0.29 & -0.31 & 0.02 & $0 \cdot 15$ & $0 \cdot 13$ \\
\hline Dietary supplements & 0.09 & 0.11 & -0.21 & 0.01 & 0.12 & 0.01 & 0.13 & -0.04 \\
\hline Variance explained (\%) & 6.04 & $5 \cdot 76$ & 4.39 & 4.07 & 3.72 & 3.54 & 3.49 & 3.45 \\
\hline
\end{tabular}

SSB, sugar-sweetened beverages.

*All bold values indicate component loadings $\geq 0.20$ considered in the naming of dietary pattern.

population and for all sex, age and ethnic groups. In the total population, a 1 SD increase in 'breakfast foods' component score was associated with a $51 \%(0 \cdot 49 ; 95 \% \mathrm{CI}$ $0.41,0.58)$ and $47 \%(0.53 ; 95 \%$ CI $0.47,0.59)$ reduction in the likelihood of meeting the $<5$ and $<10 \%$ guidelines, respectively. Similarly, in the total population, a $1 \mathrm{SD}$ increase in 'fast foods, SSB and dessert' component score was associated with a $62 \%(0 \cdot 38 ; 95 \%$ CI $0 \cdot 32,0 \cdot 44)$ and $67 \%(0.33 ; 95 \%$ CI 0.29, 0.38) reduction in the likelihood of meeting the $<5$ and $<10 \%$ guidelines, respectively.

For the total population, adherence to the 'traditional' pattern was associated with a $20 \%(0 \cdot 80 ; 95 \%$ CI 0.69, $0.93)$ and $11 \%(0.89 ; 95 \% \mathrm{CI} 0.81,0.98)$ reduction in the likelihood of meeting the $<5$ and $<10 \%$ guidelines, respectively. The association with the $<5 \%$ guideline persisted for females, adults $>30$ years and NZEO. The association with the $<10 \%$ guideline persisted for females, adults $\leq 30$ years and NZEO.

Adherence to the 'sandwich' pattern was negatively associated with meeting the $<5 \%$ recommendation for the total population $(0.77 ; 95 \%$ CI $0 \cdot 66,0.90)$ but neither positively nor negatively associated with meeting the $<10 \%$ recommendation $(0.93 ; 95 \%$ CI $0.84,1.02)$. The association with the $<5 \%$ recommendation persisted for males, both age groups and NZEO. Similarly, for the total population, adherence to the 'snack foods' pattern was negatively associated with meeting the $<5 \%$ recommendation $(0.80 ; 95 \%$ CI $0.70,0.92)$ but neither positively nor negatively associated with meeting the $<10 \%$ recommendation $(0.96 ; 95 \%$ CI $0.86,1.06)$. The association with the $<5 \%$ guideline persisted for males, adults $>30$ years and NZEO. Converse to the total population, females were less likely to meet the $<10 \%$ guideline when adhering to the 'snack foods' pattern.

Conversely, for the total population, adherence to the 'saturated fats and sugar' pattern was neither positively nor negatively associated with meeting the $<5 \%$ recommendation $(0.89$; $95 \%$ CI $0.76,1.05)$ but negatively associated with the $<10 \%$ recommendation $(0 \cdot 88 ; 95 \%$ CI $0 \cdot 81$, 0.97). The neutral association with the $<5 \%$ guideline 
Table 5 Associations between dietary patterns and meeting the $<5 \%$ TE and $<10 \%$ TE WHO free sugars intake recommendations

\begin{tabular}{|c|c|c|c|c|c|c|c|c|c|c|c|c|c|c|c|c|}
\hline & \multirow{2}{*}{\multicolumn{2}{|c|}{ Total population }} & \multicolumn{4}{|c|}{ Sex } & \multicolumn{4}{|c|}{ Age group } & \multicolumn{6}{|c|}{ Ethnicity* } \\
\hline & & & \multicolumn{2}{|r|}{ Male } & \multicolumn{2}{|c|}{ Female } & \multicolumn{2}{|c|}{$\leq 30$ years } & \multicolumn{2}{|c|}{$>30$ years } & \multicolumn{2}{|r|}{ Māori } & \multicolumn{2}{|c|}{ Pacific } & \multicolumn{2}{|r|}{ NZEO } \\
\hline & OR & $95 \% \mathrm{Cl}$ & OR & $95 \% \mathrm{Cl}$ & OR & $95 \% \mathrm{Cl}$ & OR & $95 \% \mathrm{Cl}$ & OR & $95 \% \mathrm{Cl}$ & OR & $95 \% \mathrm{Cl}$ & OR & $95 \% \mathrm{Cl}$ & OR & $95 \% \mathrm{Cl}$ \\
\hline \multicolumn{17}{|c|}{ Associations between meeting the $<5 \%$ TE WHO guideline } \\
\hline Sex (female) $\dagger$ & 0.60 & $0.41,0.87$ & & - & & - & 0.26 & $0.12,0.56$ & 0.69 & $0.44,1.07$ & 0.57 & $0.33,0.99$ & $1 \cdot 19$ & $0.63,2.22$ & 0.57 & $0.36,0.8$ \\
\hline Age & 1.00 & $1.00,1.01$ & 1.00 & $0.98,1.01$ & 1.01 & $1.00,1.03$ & & - & & - & 1.01 & $0.99,1.04$ & 1.02 & $1.00,1.03$ & 1.00 & \\
\hline \multicolumn{17}{|c|}{ 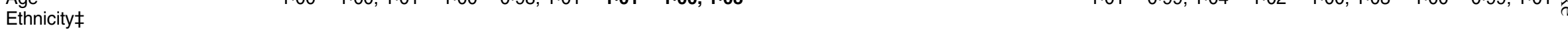 } \\
\hline Māori & 1.07 & $0.74,1.55$ & 1.06 & $0.63,1.77$ & $1 \cdot 11$ & $0.64,1.90$ & .38 & $0.60,3.18$ & 0.97 & $0.66,1.43$ & & - & & - & & - \\
\hline Pacific & 1.34 & $0.93,1.91$ & 1.01 & $0.57,1.81$ & 1.91 & $1.25,2.90$ & 1.51 & $0.74,3.10$ & 1.25 & $0.85,1.83$ & & - & & - & & - \\
\hline \multicolumn{17}{|l|}{ Dietary pattern } \\
\hline Sandwich & 0.77 & $0.66,0.90$ & 0.74 & $0.61,0.90$ & 0.80 & $0.59,1.08$ & 0.60 & $0.44,0.83$ & 0.80 & $0.67,0.97$ & 0.94 & $0.71,1.25$ & 0.82 & $0.58,1.15$ & 0.77 & 0.66 \\
\hline Fast foods, SSB and dessert & 0.38 & $0.32,0.44$ & 0.36 & $0.29,0.45$ & 0.39 & $0.31,0.48$ & 0.33 & $0.25,0.44$ & 0.39 & $0.33,0.47$ & 0.44 & $0.31,0.62$ & 0.39 & $0.31,0.48$ & 0.38 & $0.32,0.44$ \\
\hline Traditional & 0.80 & $0.69,0.93$ & 0.88 & $0.72,1.08$ & 0.70 & $0.57,0.87$ & 0.95 & $0.77,1.18$ & 0.77 & $0.65,0.92$ & 0.79 & $0.61,1.04$ & $1 \cdot 10$ & $0.88,1.39$ & 0.80 & $0.69,0.93$ \\
\hline Takea & 1.19 & $1.04,1.36$ & 1.22 & $1.05,1.41$ & 1.12 & $0.90,1.40$ & $1 \cdot 18$ & $0.94,1.48$ & $1 \cdot 16$ & $0.99,1.37$ & 1.09 & $0.91,1.29$ & 1.03 & $0.83,1.29$ & 1.19 & $1.04,1.36$ \\
\hline Breakfa & 0.49 & $0.41,0.58$ & 0.56 & $0.44,0.71$ & 0.35 & $0.26,0.49$ & 0.45 & $0.31,0.67$ & 0.48 & $0.39,0.59$ & 0.58 & $0.42,0.81$ & 0.33 & $0.21,0.53$ & 0.49 & $0.41,0.58$ \\
\hline Snack foods & 0.80 & $0.70,0.92$ & 0.78 & $0.64,0.94$ & 0.86 & $0.69,1.07$ & 0.75 & $0.55,1.03$ & 0.79 & $0.68,0.92$ & 0.91 & $0.67,1.23$ & 0.84 & $0.67,1.06$ & 0.80 & $0.70,0.92$ \\
\hline sugar & 0.89 & $0.76,1.05$ & 0.79 & $0.64,0.99$ & $1 \cdot 18$ & $0.94,1.47$ & 0.90 & $0.59,1.38$ & 0.89 & $0.74,1.06$ & 0.84 & & 0.83 & $0.62,1.12$ & 0.89 & $0.76,1.05$ \\
\hline Contemporary & 1.07 & $0.90,1.26$ & 1.01 & $0.82,1.24$ & 1.24 & $0.95,1.62$ & 0.69 & $0.46,1.02$ & $1 \cdot 17$ & $0.99,1.39$ & 0.85 & $0.58,1.25$ & $1 \cdot 13$ & $0.87,1.48$ & 1.07 & $0.90,1.26$ \\
\hline \multicolumn{17}{|c|}{ Associations between meeting the $<10 \%$ TE WHO guideline } \\
\hline Sex (female) $\dagger$ & 0.67 & $0.53,0.84$ & & - & & - & 0.36 & $0.21,0.60$ & 0.78 & $0.59,1.02$ & 0.55 & & 0.70 & 0.4 & 0.69 & .91 \\
\hline \multirow{2}{*}{\multicolumn{17}{|c|}{ 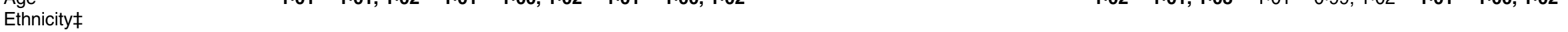 }} \\
\hline & & & & & & & & & & & & & & & & \\
\hline Māori & 09 & & $100+2+3$ & & 1.14 & & $1 \cdot 18$ & & 1.06 & & & - & & - & & - \\
\hline Pacific & 1.45 & 1.87 & 1.29 & $0.86,1.93$ & 1.62 & 1.18 & 1.52 & $0.92,2.49$ & 1.42 & $1.07,1.89$ & & - & & - & & - \\
\hline \multicolumn{17}{|l|}{ Dietary pattern } \\
\hline Sandwich & 0.93 & 02 & 0.90 & 0.8 & 0.99 & 0.8 & 0.87 & 1.04 & 0.94 & 0 & 0.89 & 0.7 & 0.86 & 1.02 & 0.95 & 0.8 \\
\hline Fast foods, SSB and dessert & 0.33 & $0.29,0.38$ & 0.37 & $0.31,0.44$ & 0.27 & $0.23,0.33$ & 0.32 & $0.25,0.41$ & 0.34 & $0.29,0.39$ & 0.32 & $0.25,0.41$ & 0.36 & $0.28,0.46$ & 0.33 & $0.29,0.39$ \\
\hline Traditional & 0.89 & $0.81,0.98$ & 0.93 & $0.82,1.05$ & 0.84 & $0.74,0.96$ & 0.81 & $0.66,0.99$ & 0.93 & $0.84,1.03$ & 0.99 & $0.82,1 \cdot 20$ & $1 \cdot 12$ & $0.93,1.34$ & 0.87 & $0.78,0.97$ \\
\hline Takeaway foods and alcohol & 1.23 & $1.11,1.35$ & 1.27 & $1.12,1.44$ & $1 \cdot 15$ & $0.99,1.33$ & $1 \cdot 18$ & $0.95,1.45$ & 1.22 & $1.09,1.36$ & 0.96 & $0.82,1.13$ & 0.95 & $0.80,1.12$ & 1.31 & $1.16,1.47$ \\
\hline Breakfast foods & 0.53 & $0.47,0.59$ & 0.57 & $0.49,0.66$ & 0.47 & $0.40,0.56$ & 0.61 & $0.48,0.76$ & 0.50 & $0.44,0.57$ & 0.54 & $0.45,0.64$ & 0.49 & $0.40,0.60$ & 0.53 & $0.46,0.61$ \\
\hline Snack foods & 0.96 & $0.86,1.06$ & 1.02 & $0.90,1 \cdot 16$ & 0.84 & $0.72,0.98$ & 0.84 & $0.69,1.03$ & 0.97 & $0.87,1.09$ & 0.91 & $0.73,1.12$ & 0.97 & $0.72,1.32$ & 0.95 & $0.85,1.06$ \\
\hline Saturated fats & 0.88 & $0.81,0.97$ & 0.87 & $0.78,0.98$ & 0.90 & $0.78,1.05$ & 0.83 & $0.67,1.04$ & 0.88 & $0.79,0.98$ & 0.88 & $0.73,1.06$ & 0.87 & $0.65,1.15$ & 0.88 & $0.79,0.97$ \\
\hline Contemporary & 1.06 & $0.97,1.16$ & 1.17 & $1.04,1.31$ & 0.88 & $0.76,1.03$ & 1.02 & $0.85,1.22$ & 1.04 & $0.93,1.16$ & 0.93 & $0.76,1.14$ & 0.99 & $0.81,1.21$ & 1.08 & $0.97,1.20$ \\
\hline
\end{tabular}

TE, total energy; NZEO, New Zealand European and other; SSB, sugar-sweetened beverages.

All bold values were significantly positively or negatively associated with meeting the $<5$ or $<10 \%$ TE recommendation $(P<0.05)$.

*Prioritised ethnicity used for all analyses by ethnicity.

TMales used as the reference category. 
persisted for all subgroups except for males, while the negative association with the $<10 \%$ guideline persisted for males, adults $>30$ years and NZEO.

The 'takeaway foods and alcohol' pattern was more strongly associated with meeting the $<10 \%$ WHO guideline than the $<5 \%$ guideline. The 'sandwich', 'traditional', 'breakfast foods' and 'snack foods' patterns were more strongly negatively associated with meeting the $<5 \%$ guideline than with the $<10 \%$ guideline. Conversely, the 'fast foods, SSB and dessert' and 'saturated fats and sugar' patterns were more strongly negatively associated with meeting the $<10 \%$ guideline than with the $<5 \%$ guideline.

\section{Discussion}

As far as we are aware, this is the first NZ study - and the second globally - to examine adults' dietary patterns specifically associated with meeting the WHO free sugars guideline ${ }^{(33)}$. Dietary patterns were derived using a representative sample of the NZ adult population. The eight unique dietary patterns identified were termed 'sandwich', 'fast foods, SSB and dessert', 'traditional', 'takeaway foods and alcohol', 'breakfast foods', 'snack foods', 'saturated fats and sugar' and 'contemporary'. The 'takeaway foods and alcohol' pattern was positively associated with meeting both the $<5$ and $<10 \%$ free sugars guidelines. The "contemporary' pattern was neither positively nor negatively associated with the guideline in the total population, but was associated with the $<10 \%$ guideline in males only. The 'fast foods, SSB and dessert', 'traditional' and 'breakfast foods' patterns were negatively associated with both the $<5$ and $<10 \%$ guidelines. The 'sandwich' and 'snack foods' patterns were negatively associated with the $<5 \%$ guideline only, while the 'saturated fats and sugar' pattern was negatively associated with the $<10 \%$ guideline only.

The 'takeaway foods and alcohol' pattern was characterised by fish and seafood, potato products, takeaway foods and alcoholic beverages. The fish and seafood food group, containing battered, fried and crumbed fish, and the potato products food group, containing hot chips and wedges, are commonly purchased together from takeaway stores as 'fish and chips' in $\mathrm{NZ}^{(34)}$. While this dietary pattern was low in free sugars, it was likely high in energy, saturated fat and $\mathrm{Na}^{(35)}$. A 2019 analysis of the UK National Diet and Nutrition Survey using latent class analysis found that 'prudent eaters' and 'high fat consumers' similarly met the WHO free sugars guideline ${ }^{(33)}$. Prudent eaters consumed the highest proportion of alcohol and fish as well as fat spreads and fruit, while high fat consumers had the highest intakes of meat and dairy but lowest fish intakes ${ }^{(33)}$. Comparable with the present findings, neither pattern met the WHO saturated fat or $\mathrm{Na}$ intake guideline ${ }^{(33)}$. These findings indicate that it is possible to meet the WHO free sugars guideline while consuming an energydense, nutrient-poor dietary pattern, and that prevalent groups across populations are consuming such diets. These diets high in saturated fats, $\mathrm{Na}$ and alcohol are similar to diets high in free sugars - they are associated with poor health outcomes ${ }^{(26)}$.

The 'fast foods, SSB and desserts' and 'saturated fats and sugar' patterns were characterised by the consumption of energy-dense food groups and food groups proportionally high in free sugars. The 'sandwich', 'traditional', 'breakfast foods' and 'snack foods' patterns were positively characterised by food groups high in free sugars and nutrient-dense (e.g., fruit and vegetables) food groups. The 'fast foods, SSB and desserts', 'breakfast foods' and 'saturated fats and sugar' patterns were additionally characterised by low intakes of nutrient-dense food groups. Nonetheless, all four patterns were negatively associated with meeting the free sugars guideline. Similarly, the aforementioned UK study found a 'high sugar/high fat consumers' group consuming high free sugars and nutrient-dense food groups (cereals, vegetables and potatoes), and a 'junk food eaters' group lacking nutrient-dense food groups (fruit) and consuming high free sugars (confectionary and potentially nonalcoholic beverages) ${ }^{(33)}$. The current study did not distinguish between low-sugar and SSB in their non-alcoholic beverage food group, so it is unknown whether beverages contributed to the group not meeting the WHO guideline. Two studies conducted on children in high-income countries have likewise found associations between dietary patterns and high free sugars intake ${ }^{(36,37)}$. Ambrosini et al. ${ }^{(37)}$ identified an 'energy-dense' pattern in English children characterised by the consumption of food groups high in sugars (confectionary, cakes and biscuits and SSB) and low intakes of nutrient-dense food groups (fruit, vegetables and high-fibre breads and cereals). Ambrosini et al.$^{(37)}$ also identified a 'non-energy-dense pattern' characterised by the consumption of food groups high in sugar (SSB, fruit juices and breakfast cereals) and low intakes of milk, margarines and oils, cheese and crisps $^{(37)}$. Farajian et al. ${ }^{(36)}$ similarly identified 'pattern one' characterised by the consumption of refined carbohydrates (sweets, fast foods and SSB) and 'pattern 2' characterised by the consumption of food groups high in sugar (SSB, fruit juices and sweet spreads) and nutrient-dense food groups (vegetables and legumes). Comparable to the present findings, previously identified dietary patterns associated with high free sugars intake were characterised by the consumption of energy-dense food groups, food groups proportionally high in free sugars and nutrient-dense food groups. This evidence suggests that consuming an overall dietary pattern dense in free sugars or frequently consuming individual foods high in free sugars may lead individuals to exceed the WHO free sugars guideline.

With regard to beverage intake profiles, associations between the 'fast foods, SSB and desserts' and 'contemporary' dietary patterns and the WHO free sugars guideline were consistent with prior studies. The 'fast foods, SSB and desserts' dietary pattern, which was negatively 
associated with the WHO guideline, was characterised by high intakes of SSB and low intakes of low-sugar beverages. The 'contemporary' pattern, which was positively associated with meeting the $<10 \%$ WHO guideline for males, was characterised by high intakes of low-sugar beverages. High intakes of SSB or fruit juice were common to all aforementioned dietary patterns associated with high free sugars intake identified by Ambrosini et al. ${ }^{(37)}$ and Farajian et al. ${ }^{(36)}$. An analysis of British adults' beverage consumption found that those who solely consumed low-calorie beverages were nine times less likely to exceed $<5 \% \mathrm{TE}$ from free sugars than those who solely consumed $\mathrm{SSB}^{(38)}$. A dietary pattern characterised by an unhealthy beverage profile may be somewhat predictive of not meeting the WHO guideline as SSB have a low satiety value, in addition to being dense in sugars ${ }^{(39)}$. Consequently, SSB consumption has been linked with weight gain as the energy consumed through SSB is not wholly compensated for by reduced energy intake from other foods and beverages ${ }^{(39)}$.

The majority of the most prevalent dietary patterns that explained the largest amount of variance in NZ adults' diets were associated with not meeting the WHO free sugars guideline. The 'fast foods, SSB and dessert' and 'breakfast foods' patterns were associated with not meeting both guidelines. The 'sandwich' and 'snack foods' patterns were associated with not meeting the $<5 \%$ guideline only, and the 'saturated fats and sugar' pattern was associated with not meeting the $<10 \%$ guideline only. To date, studies identifying dietary patterns comprising similar food groups have reported stronger associations with short-term chronic disease risk factors than with longer-term disease. A 'fast foods/dessert' dietary pattern was associated with higher energy, fat and saturated fat intakes and metabolic syndrome in Lebanese adults ${ }^{(40)}$. A 'fast energy' dietary pattern was also associated with increased risk of metabolic syndrome in Swedish adults ${ }^{(41)}$. A 'high fat/sugar/takeaway' pattern was associated with shorter maternal gestation and infant birth length in Australian women ${ }^{(42)}$. A 'high sugar/high fat consumers' pattern was associated with high free sugars, total fat, and saturated fat and low fruit and vegetables and dietary fibre intakes ${ }^{(33)}$. A 'bread and butter' pattern was associated with a higher risk of type 2 diabetes in Native Canadians ${ }^{(43)}$, and a 'white bread' pattern was inversely associated with HDL-cholesterol in American men $^{(44)}$. No association was found between a 'high-white bread' or 'high-salty snacks' pattern and adenocarcinoma of the oesophagus and distal stomach in Nebraskan adults ${ }^{(45)}$. Similarly, no significant association was found between a 'Western breakfast' pattern and stomach cancer in Japanese men ${ }^{(46)}$, but a 'breakfast foods' pattern was associated with a lower risk of impaired glucose tolerance in Hispanic elders ${ }^{(47)}$. In contrast to the present findings, Farajian et al. ${ }^{(36)}$ reported that consuming breakfast more frequently or eating a greater number of meals and snacks was associated with lower free sugars intake in Greek children. It is, therefore, highly plausible that consuming breakfast and snacking are not inherently negatively associated with meeting the WHO guideline, but that it was the breakfast or snack foods and beverages selected by NZ adults that led to higher free sugars intake.

The 'traditional' pattern, characterised by foods traditional to NZ culture, including red meats, starchy and non-starchy vegetables, savoury sauces and condiments, puddings and desserts, and cakes and muffins, was also negatively associated with meeting the WHO free sugars guideline. Studies identifying traditional patterns that comprise similar food groups have found inconsistent associations with health outcomes, including higher risks of gastric cancer in Italians ${ }^{(48)}$, raised total and HDL-cholesterol, glucose and systolic blood pressure in Dutch adults ${ }^{(49)}$, but no association with high blood pressure in European women $^{(50)}$ or prostate cancer in American men ${ }^{(51)}$. Studies have also reported associations with both higher $\mathrm{BMI}^{(52,53)}$ and lower $\mathrm{BMI}^{(54,55)}$ in comparison to other derived patterns. These inconsistent findings may be due to the slight variations between countries in what is incorporated in a traditional diet. However, a similar 'traditional' pattern previously identified in NZ adults was positively characterised by starchy vegetables, other vegetables, red and other meats, sugars and preserves, cream, regular milk (2.5-4.0 \% fat), coffee and tea, and negatively characterised by takeaway foods. This pattern was positively associated with BMI and waist circumference in some but not all NZ adults $^{(53)}$

A strength of the current study was the use of a large ( $n$ 4721) nationally representative sample. Oversampling of Māori, Pacific, and younger and older age groups allowed sufficient statistical power to make comparisons by sex, age and ethnicity. The NZANS additionally collected repeat 24-h dietary recall data. Singular 24-h dietary recalls were designed to quantitatively assess actual dietary intake over the past $24 \mathrm{~h}$ and are, therefore, not representative of individuals' usual intake ${ }^{(56)}$. However, repeat NZANS recall data allowed dietary intake to be adjusted for intraindividual variation to estimate usual intake using the web-based programme MSM. MSM requires at least two independent days of dietary intake data and has previously been shown to be effective, even for food groups with high proportions of non-consumers ${ }^{(57)}$. FFQ data, further days of dietary intake data and a large sample size all lead to better estimates of usual intake ${ }^{(57)}$. Repeat recall data was collected for $25 \%$ of NZANS participants, but an FFQ was not conducted in the NZANS. However, NZANS remains the most appropriate data source as it is the most recent and largest nationally representative dietary survey for NZ.

A limitation of the diet recall method is its use of retrospective questioning, which relies on participants' memory and thus provides the opportunity for misreporting food and beverage intake ${ }^{(56)}$. Gemming et al. ${ }^{(14)}$ reported that $25 \%$ of women and $21 \%$ of men in NZANS were 
low-energy reporters, with higher proportions of overweight, obese, Pacific and adults over 65 years reporting low energy intakes. Underreporting may have been exacerbated for food groups dense in free sugars due to social desirability bias ${ }^{(58)}$. Consequently, the proportion of participants meeting the WHO free sugars guideline in NZ may have been overestimated. The underreporting of specific energy-dense food groups may have produced some correlated measurement error by increasing or decreasing correlations between energy-dense and other food groups and, subsequently, distorting the patterns produced ${ }^{(30)}$. NZ adults' dietary patterns may have also changed since 2008/2009. Additionally, the earlier estimation of free sugars in foods introduced some subjectivity ${ }^{(13)}$. However, $92 \%$ of these food composition estimates were able to be made using objective methods, which reduced the potential for bias ${ }^{(13)}$. Despite the inherent limitations of diet recalls, they are an appropriate population-based dietary assessment method ${ }^{(56)}$.

A literature review of the strengths and limitations of $a$ posteriori dietary pattern derivation methods indicated that no one method was better than another ${ }^{(30,44,59,60)}$. In contrast to cluster analysis, PCA aggregates foods rather than participants, which was advantageous for the purposes of the current study. However, PCA did require some subjective decisions to be made, such as the grouping of foods. Due to the design of NZANS, some foods, such as chocolate nut spreads and other nut butters, could not be disaggregated from foods they were originally grouped with, which had similar ingredients but different nutrient compositions. Grouping foods was largely up to the authors' discretion, though. The additional disaggregation of food groups in the current study, such as low-sugar beverages and SSB, led to patterns that could not be more easily and accurately interpreted than previous papers of a similar nature. Additional subjective decisions included the number of components to retain, method of rotation and the naming of dietary patterns. For example, the 'takeaway foods and alcohol' dietary pattern was partially named as such based on the correlation between the 'fish and seafood' and 'potato products' food groups and the assumption that these were purchased as fish and chips from takeaway stores. Furthermore, the 'traditional' pattern could alternatively have been named 'Western'. To reduce this subjectivity, critical decisions were made based on recommendations in the literature and following discussion between co-authors. More objective measures, such as Kaiser's criterion and scree plots, were used where possible. Additionally, the present dietary patterns only explained $34 \%$ of the total variance in dietary intake. However, this is similar or higher than that explained by other studies ${ }^{53,61-63)}$.

Nonetheless, the investigation of dietary patterns was in itself a strength, as free sugars and foods high in free sugars are not consumed in isolation but as part of meals and snacks to form a complete diet ${ }^{(64)}$. The presented results provide an insight into the ways in which NZ adults commonly combine foods and beverages to form diets that might or might not meet the WHO free sugars guideline. The patterns presently derived are specific to NZ adults as dietary patterns can differ between cultures and geographic locations. However, similar high-income populations with a comparable food supply could also see such associations with the WHO guideline if they consumed the presently derived dietary patterns. The use of datadriven a posteriori methods, as opposed to theoretically driven a priori methods, was a further strength, as the derived dietary patterns were not limited by current nutrition knowledge or the selected definition of a 'healthy diet'. Moreover, the dietary patterns were formed using preexisting correlations between food groups in NZ adults' diets and thus, although largely negatively associated with meeting the WHO guideline, were inherently feasible to achieve. By way of considering food groups as a whole rather than specific foods or beverages, low- or high-cost versions of dietary patterns could also be adopted. For example, non-alcoholic beverages within the 'contemporary' pattern could consist of cheap municipal tap water or more expensive barista-made coffees.

\section{Conclusions}

The current study provided insights into the dietary patterns of NZ adults, which may be used in the design and implementation of public health policies and interventions aimed at reducing free sugars intakes in both NZ and other high-income countries with similar dietary patterns. Results showed that the majority of NZ adults' dietary patterns do not meet the WHO free sugars guideline. All eight dietary patterns differed in composition, but all needed to be altered to varying degrees to reflect a healthy diet that would meet WHO free sugars recommendations and other nutrient recommendations. The 'takeaway foods and alcohol' dietary pattern, which was associated with meeting both WHO free sugars guidelines, showed that it is possible to meet the free sugars guideline while consuming an energy-dense, nutrient-poor diet. A 'contemporary' pattern, associated with meeting the $<10 \%$ guideline in males, did instead include fewer energy-dense food groups and more nutrient-dense food groups. Efforts to reduce free sugars intake would, therefore, benefit from promoting more overall healthy diets rich in sources of whole grains, lean protein, PUFA and MUFA and unsweetened beverages - a message consistent with the current NZ dietary guidelines. Simultaneously implementing evidence-based policies to reduce the consumption of specific foods high in free sugars, saturated fats and $\mathrm{Na}$, and healthier reformulation of processed foods would provide the greatest population health benefits; the latter is an advantageous adjunct to promoting behaviour changes because it requires little to no participant agency. Further research is warranted to 
quantify the potential health and financial gains that may be achieved by reducing free sugars intake to $<10 \%$ TE as well as the most effective interventions and policies to do so.

\section{Acknowledgements}

Acknowledgements: Data from the 2008/2009 NZANS was supplied by the University of Otago's Life in New Zealand staff (Blakey, Smith and Parnell, personal communication). Kibblewhite and Nettleton at the Department of Human Nutrition, University of Otago added free sugars to the New Zealand Food Composition Database. The NZ Ministry of Health funded the 2008/2009 NZANS. The New Zealand Crown is the owner of the copyright for the survey data. The results presented in this paper are the work of the authors conducted as part of the requirements of a Master of Dietetics at the University of Otago. Financial support: This work was supported by the Health Research Council of New Zealand (grant number 13/724, 16/443). The Health Research Council of New Zealand had no role in the design, analysis or writing of this article. Conflict of interest: None. Authorship: H.E. and C.N.M. conceived of the research idea and acquired funding; C.S. obtained data, performed the PCA, analysed the data and drafted the manuscript; H.E., L.T.M. and C.C. assisted with methodological development decisions and supervised C.S.'s Master of Dietetics thesis (C.C. was the primary supervisor); all authors reviewed the manuscript. Ethics of human subject participation: The current study was conducted according to the guidelines laid down in the Declaration of Helsinki, and all procedures involving human subjects were approved by the New Zealand Health and Disability Multi-Region Ethics Committee. Written informed consent was obtained from all subjects.

\section{References}

1. Moynihan PJ \& Kelly SA (2014) Effect on caries of restricting sugars intake: systematic review to inform WHO guidelines. $J$ Dent Res 93, 8-18.

2. Te Morenga L, Mallard S \& Mann J (2013) Dietary sugars and body weight: systematic review and meta-analyses of randomised controlled trials and cohort studies. $\mathrm{Br} \mathrm{Med} \mathrm{J}$ 346, e7492.

3. Te Morenga LA, Howatson AJ, Jones RM et al. (2014) Dietary sugars and cardiometabolic risk: systematic review and metaanalyses of randomized controlled trials of the effects on blood pressure and lipids. Am J Clin Nutr 100, 65-79.

4. Fattore E, Botta F, Agostoni C et al. (2017) Effects of free sugars on blood pressure and lipids: a systematic review and meta-analysis of nutritional isoenergetic intervention trials. Am J Clin Nutr 105, 42-56.

5. Yang Q, Zhang Z, Gregg EW et al. (2014) Added sugar intake and cardiovascular diseases mortality among us adults. JAMA Intern Med 174, 516-524.
6. Malik VS, Popkin BM, Bray GA et al. (2010) Sugar-sweetened beverages and risk of metabolic syndrome and type 2 diabetes: a meta-analysis. Diabetes Care 33, 2477-2483.

7. Malik VS, Pan A, Willett WC et al. (2013) Sugar-sweetened beverages and weight gain in children and adults: a systematic review and meta-analysis. Am J Clin Nutr 98, 1084-1102.

8. World Health Organization (2015) Guideline: Sugars Intake for Adults and Children. Geneva: World Health Organization.

9. Lei L, Rangan A, Flood VM et al. (2016) Dietary intake and food sources of added sugar in the Australian population. Br J Nutr 115, 868-877.

10. Sluik D, van Lee L, Engelen AI et al. (2016) Total, free, and added sugar consumption and adherence to guidelines: the Dutch national food consumption survey 2007-2010. Nutrients 8, e70.

11. Public Health England \& Food Standards Agency (2016) National Diet and Nutrition Survey. Results from Years 5 and 6 (Combined) of the Rolling Programme (2012/20132013/2014). London: Public Health England.

12. Welsh JA, Sharma AJ, Grellinger L et al. (2011) Consumption of added sugars is decreasing in the United States. Am J Clin Nutr 94, 726-734.

13. Kibblewhite R, Nettleton A, McLean R et al. (2017) Estimating free and added sugar intakes in New Zealand. Nutrients 9, 1292 .

14. Gemming L, Jiang Y, Swinburn B et al. (2014) Underreporting remains a key limitation of self-reported dietary intake: an analysis of the 2008/09 New Zealand Adult Nutrition Survey. Eur J Clin Nutr 68, 259-264.

15. Gemming L \& Ni Mhurchu C (2016) Dietary under-reporting: what foods and which meals are typically under-reported? Eur J Clin Nutr 70, 640-641.

16. Organisation for Economic Co-operation and Development (2017) Obesity Update 2017, pp. 16. France: Organisation for Economic Co-operation and Development.

17. Ministry of Health (2017) Annual Data Explorer 2016/17: New Zealand Health Survey [Data File]. Wellington: Ministry of Health.

18. Ministry of Health (2006) Food and Nutrition Monitoring Report 2006, pp. 94. Wellington: Ministry of Health.

19. Ministry of Health (2010) Key Findings of the 2009 New Zealand Oral Health Survey, pp. 331. Wellington: Ministry of Health.

20. Hu FB (2002) Dietary pattern analysis: a new direction in nutritional epidemiology. Curr Opin Lipidol 13, 3-9.

21. Selwitz RH, Ismail AI \& Pitts NB (2007) Dental caries. Lancet 369, 51-59.

22. Hodge A \& Bassett J (2016) What can we learn from dietary pattern analysis? Public Health Nutr 19, 191-194.

23. University of Otago \& Ministry of Health (2011) Methodology Report for the 2008/09 New Zealand National Nutrition Survey, pp. 91. Wellington: Ministry of Health.

24. University of Otago \& Ministry of Health (2011) A Focus on Nutrition: Key Findings of the 2008/09 New Zealand Adult Nutrition Survey, pp. 360. Wellington: Ministry of Health.

25. Her Majesty's Revenue and Customs (2016) Policy Paper: Soft Drinks Industry Levy. https://www.gov.uk/government/ publications/soft-drinks-industry-levy/soft-drinks-industrylevy (accessed April 2017).

26. Forouzanfar MH, Alexander L, Bachman VF et al. (2015) Global, regional, and national comparative risk assessment of 79 behavioural, environmental and occupational, and metabolic risks or clusters of risks in 188 countries, 1990-2013: a systematic analysis for the Global Burden of Disease Study 2013. Lancet 386, 2287-2323.

27. Harttig U, Haubrock J, Knüppel S et al. (2011) The MSM program: web-based statistics package for estimating usual dietary intake using the multiple source method. Eur J Clin Nutr 65, Suppl. 1, S87-S91. 
28. Steele CS (2017) Dietary patterns associated with meeting the World Health Organization free sugar guidelines in New Zealand adults. Master of Dietetics Thesis, University of Otago.

29. Varraso R, Garcia-Aymerich J, Monier F et al. (2012) Assessment of dietary patterns in nutritional epidemiology: principal component analysis compared with confirmatory factor analysis. Am J Clin Nutr 96, 1079-1092.

30. Michels KB \& Schulze MB (2005) Can dietary patterns help us detect diet-disease associations? Nutr Res Rev 18, 241-248.

31. StataCorp (2015) Stata Statistical Software: Release 15. College Station, TX: StataCorp LP.

32. Louie JC, Moshtaghian H, Boylan S et al. (2015) A systematic methodology to estimate added sugar content of foods. EurJ Clin Nutr 69, 154-161.

33. Nocella G \& Srinivasan CS (2019) Adherence to WHO's nutrition recommendations in the UK: dietary patterns and policy implications from a national survey. Food Policy 86, 101719.

34. Holloway C (2017) Fish and Chips Are Still Top Dog in New Zealand. https://www.nielsen.com/nz/en/insights/ article/2017/fish-and-chips-are-still-top-dog-in-new-zealand/ (accessed January 2019).

35. Eyles H, Jiang Y, Blakely T et al. (2018) Five year trends in the serve size, energy, and sodium contents of New Zealand fast foods: 2012 to 2016. Nutr J 17, 65.

36. Farajian P, Risvas G, Panagiotakos DB et al. (2016) Food sources of free sugars in children's diet and identification of lifestyle patterns associated with free sugars intake: the GRECO (Greek Childhood Obesity) study. Public Health Nutr 19, 2326-2335.

37. Ambrosini GL, Johns DJ, Northstone K et al. (2016) Free sugars and total fat are important characteristics of a dietary pattern associated with adiposity across childhood and adolescence. J Nutr 146, 778-784.

38. Patel L, Alicandro G \& La Vecchia C (2018) Low-calorie beverage consumption, diet quality and cardiometabolic risk factors in British adults. Nutrients 10, 1261.

39. Pan A \& Hu FB (2011) Effects of carbohydrates on satiety: differences between liquid and solid food. Curr Opin Clin Nutr Metab Care 14, 385-390.

40. Naja F, Nasreddine L, Itani L et al. (2013) Association between dietary patterns and the risk of metabolic syndrome among Lebanese adults. Eur J Nutr 52, 97-105.

41. Berg CM, Lappas G, Strandhagen E et al. (2008) Food patterns and cardiovascular disease risk factors: the Swedish INTERGENE research program. Am J Clin Nutr 88, 289-297.

42. Grieger JA, Grzeskowiak LE \& Clifton VL (2014) Preconception dietary patterns in human pregnancies are associated with preterm delivery. J Nutr 144, 1075-1080.

43. Gittelsohn J, Wolever TMS, Harris SB et al. (1998) Specific patterns of food consumption and preparation are associated with diabetes and obesity in a native Canadian Community. J Nutr 128, 541-547.

44. Newby PK, Muller D \& Tucker KL (2004) Associations of empirically derived eating patterns with plasma lipid biomarkers: a comparison of factor and cluster analysis methods. Am J Clin Nutr 80, 759-767.

45. Chen H, Ward MH, Graubard BI et al. (2002) Dietary patterns and adenocarcinoma of the esophagus and distal stomach. Am J Clin Nutr 75, 137-144.

46. Masaki M, Sugimori H, Nakamura KI et al. (2003) Dietary patterns and stomach cancer among middle-aged male workers in Tokyo. Asian Pac J Cancer Prev 4, 61-66.
47. Lin H, Bermudez OI \& Tucker KL (2003) Dietary patterns of Hispanic elders are associated with acculturation and obesity. J Nutr 133, 3651-3657.

48. Palli D, Russo A \& Decarli A (2001) Dietary patterns, nutrient intake and gastric cancer in a high-risk area of Italy. Cancer Causes Control 12, 163-172.

49. Van Dam RM, Grievink L, Ocké MC et al. (2003) Patterns of food consumption and risk factors for cardiovascular disease in the general Dutch population. Am J Clin Nutr 77, 1156-1163.

50. Schulze MB, Hoffmann K, Kroke A et al. (2003) Risk of hypertension among women in the EPIC-Potsdam Study: comparison of relative risk estimates for exploratory and hypothesis-oriented dietary patterns. Am J Epidemiol 158, 365-373.

51. Tseng M, Breslow RA, DeVellis RF et al. (2004) Dietary patterns and prostate cancer risk in the National Health and Nutrition Examination Survey Epidemiological Follow-Up Study cohort. Cancer Epidem Biomar 13, 71-77.

52. Greenwood DC, Cade JE, Draper A et al. (2000) Seven unique food consumption patterns identified among women in the UK Women's Cohort Study. Eur J Clin Nutr 54, 314-320.

53. Beck KL, Jones B, Ullah I et al. (2017) Associations between dietary patterns, socio-demographic factors and anthropometric measurements in adult New Zealanders: an analysis of data from the 2008/09 New Zealand Adult Nutrition Survey. Eur J Nutr 57, 1421-1433.

54. Pryer JA, Cook A \& Shetty P (2001) Identification of groups who report similar patterns of diet among a representative national sample of British adults aged 65 year of age or more. Public Health Nutr 4, 787-795.

55. Sichieri R (2002) Dietary patterns and their associations with obesity in the Brazilian city of Rio de Janeiro. Obes Res 10, $42-48$.

56. Gibson RS (2005) Principles of Nutritional Assessment, 2nd ed. New York: Oxford University Press.

57. Haubrock J, Nöthlings U, Volatier JL et al. (2011) Estimating usual food intake distributions by using the multiple source method in the EPIC-Potsdam Calibration Study. J Nutr 141 914-920.

58. Poppitt SD, Swann D, Black AE et al. (1998) Assessment of selective under-reporting of food intake by both obese and non-obese women in a metabolic facility. Int $J$ Obes $\mathbf{2 2}$, 303-311.

59. Reedy J, Wirfalt E, Flood A et al. (2010) Comparing 3 dietary pattern methods-cluster analysis, factor analysis, and index analysis-with colorectal cancer risk: The NIH-AARP Diet and Health Study. Am J Epidemiol 171, 479-487.

60. Newby PK \& Tucker KL (2004) Empirically derived eating patterns using factor or cluster analysis: a review. Nutr Rev 62, 177-203.

61. Lennon LT, Papacosta O, Wannamethee SG et al. (2016) Dietary patterns and the risk of CVD and all-cause mortality in older British men. Br J Nutr 116, 1246-1255.

62. Machado Arruda SP, da Silva AAM, Kac G et al. (2016) Dietary patterns are associated with excess weight and abdominal obesity in a cohort of young Brazilian adults. Eur J Nutr 55, 2081-2091.

63. Howe AS, Black KE, Wong JE et al. (2013) Dieting status influences associations between dietary patterns and body composition in adolescents: a cross-sectional study. Nutr J 12, 51 .

64. Kant AK (2004) Dietary patterns and health outcomes. J Am Diet Assoc 104, 615-635. 